\title{
Age at Menarche among the School Going Children of Jorpati, Kathmandu
}

\author{
Usha Chalise, ${ }^{1}$ Allin Pradhan, ${ }^{1}$ Chhiring Palmu Lama, ${ }^{1}$ Prem Prasad Panta, ${ }^{2}$ Shaligram Dhungel ${ }^{1}$ \\ ${ }^{1}$ Deparment of Anatomy, ${ }^{2}$ Department of Community Medicine, Nepal Medical College and Teaching Hospital, \\ Kathmandu, Nepal.
}

\begin{abstract}
Background: The present study was conducted to explore the mean age at menarche and associating factors among the Nepali school girls of Jorpati, Kathmandu. Materials and Methods: This descriptive cross-sectional study had 500 girls of age between 9-18 years from the school of Gokarneshowr Municipality, Jorpati, Kathmandu. The data collected were tabulated and analyzed by using SPSS 16. Results: The age at menarche of the respondents was $12.56 \pm 1.12$ years and menarchial age varied from 9-16 years. Similarly, the mean age at menarche of sisters and mothers were $12.96 \pm 1.25$ and $14.30 \pm 1.58$ respectively. The mean age at menarche of vegetarian group was 12.41 years as compared to non-vegetarian was 12.59 years. The lowest mean age at menarche was in Newar (12.31 years) and highest mean age at menarche in Brahmin/Chhetriwas (12.67 years). Followed by age at menarche in Mongoloids was (12.52 years)and others (12.61 years). Conclusions: There was decrease in age at menarche with successive generation as a result of increase in urbanization, better dwelling and smaller family size as compared to previous generation.
\end{abstract}

Keywords: adolescent; age at menarche; obesity; school going children.

\section{INTRODUCTION}

The term menarche was introduced into the medical literature by Kisch. ${ }^{1}$ The normal reproductive years of the female are characterized by monthly rhythmical changes in the rates of secretion of the female hormones and corresponding physical changes in the ovaries and other sexual organs. This rhythmical pattern is called female monthly sexual cycle (menstrual cycle). Menarche indicates the specific stage of first periodical regular flow of blood from the uterus in all healthy female.,

The ovarian changes that occur during the sexual cycle depends completely on the gonadotropic hormones, FSH and LH, secreted by the anterior pituitary gland. In the absence of these hormones, the ovaries remain inactive, which is the case throughout childhood, when almost no pituitary gonadotrophic hormones are secreted. ${ }^{4,5}$ At the age of $8-12$ years, the pituitary gland begins to secrete progressively more FSH and $\mathrm{LH}$, which leads to onset of normal monthly sexual cycles beginning between the ages of 11 and 16 years. This period of changes is called puberty and the time of first menstrual cycle is called Menarche., Menarcheal age serves as an easily identifiable marker for developmental status relative to same age peers. $^{2}$ The enhanced living situation has been reported for the early onset of menarche in both developed and developing countries. ${ }^{6-9}$ The age at menarche is not fixed but varies in different ethnic groups. It may vary with races, size of the family and environmental factors. ${ }^{2,10,11}$ Reports have shown that, age at menarche varies with passage of time, occurring earlier than it did (earlier in new generation than old generation). ${ }^{2,9,10,12}$ Menarche tends to occur earlier in higher social class and in urban surroundings due to food habits (junk food) and use of internet causing early maturity. ${ }^{13,14}$ Several reports were found stating that the females having early menarche have elevated risk for breast cancer. ${ }^{2}$

According to World Health Organization (WHO), adolescence is a period between 10-19 years. The menarche is the most notable event during female puberty. Though the menstruation is a part of the normal physiological phenomenon occurring at reproductive period in females, variation in menarchial pattern is frequently observed among the adolescents. Dysmenorrhea

Correspondence: Dr. Usha Chalise, Department of Anatomy, Nepal Medical College and Teaching Hospital, Kathmandu, Nepal. Email: drushachalise@gmail.com. Phone: +977-9841214995. DOI: 10.3126/ jcmsn.v14i3.19916 Article received: 2018-05-16. Article accepted: 2018-09-10. 
(lower abdominal pain during menstruation, backache, nausea and vomiting) is a major problem during menstruation affecting the females daily activity even including school absenteeism. ${ }^{15}$ Another study conducted among the Nursing student of Birgunj, concluded that the age at menarche was 13-14 years. The majority of girls were unprepared for suchphenomenon. It was a frightening experience with very little knowledge about maintaining menstrual hygiene. The rituals observed during the period were mentioned that they were kept isolated in dark room and away from the parents. $^{3}$

The study aimed to find out the effect of Body Mass Index (BMI) and nutritional status on the menstrual pattern in adolescent girl concluded that low level of hemoglobin and nutritional status is frequently corelated with irregularities of menstruation. Due to change in life style, habits, diet, the prevalence of obesity has increased in developing world which results in decreased age at menarche. ${ }^{16}$ Since this study was conducted in Kathmandu valley where comparatively better living standard, stressful life, pollution and scarcity of leisure time is more than other part of country. These factors are considered as predisposing factors, that is influencing the age at menarche. The main aim of the study was to find out the age at menarche and the associating factors among the school girls of Jorpati.

\section{MATERIALS AND METHODS}

The study was conducted in seven schools of Gokarneshwor Municipality, Kathmandu. It was descriptive cross-sectional study and the study population was female students between the age of 9 -18 years of selected schools. Based on the study conducted on Pokhara valley, ${ }^{11}$ keeping 95\% confidence interval and 31days of permissible error and the standard deviation as 0.9 , the total number of students were calculated as $n=420$ using formula $\mathrm{n}=\mathrm{Z}^{2} \sigma^{2} / \mathrm{d}^{2}$. The total number of participants included in the study was 500. Ethical approval has been taken from Nepal Health Research Council (Ref No1671) for this study. The permission was also taken from the selected school authority. Since all the study sites are Co-educational school, first of all, the male students were separated and only female students were in the class room. Then the main objective, advantages and disadvantages of the study were explained to the students. The consent and assent form were sent to the willing students. The study included only the students who brought back the consent and assent form. In addition, the students were also explained that their participation was only once and they can withdraw in anytime from the study. The healthy girls between the age of 9-18 years without any growth-related disorder and genetic abnormalities were included in the study while those who had not attended menarche at the time of the study and who could not remember exact date of menarche were excluded from the study. After being selected for the study the girls were provided with the questionnaire that was written in Nepali language.

To measure the height of the girls, they were asked to stand straight in contact with vertical wall looking forward, while the weight was calculated by asking the girls to stand on both feet in the center of weighing machine. The data, thus collected was tabulated and analyzed by using SPSS 16. The mean age at menarche of the participants was calculated, Anova test and correlation coefficient were calculated to determine the significant level $(p=0.05)$ between the factors of menarche.

\section{RESULTS}

The 500 respondents were surveyed to find out the age at menarche. Out of 500 respondents, 62 respondents reported that menarche had not started. Therefore, the analysis was performed only of 438 respondents. The mean age of the respondents was 14.69 years with standard deviation of 2.25 years. The age ranges of the study were between 9-18 years. Likewise, the mean age at menarche of the respondents was 12.56 years with standard deviation of 1.12 years and menarcheal age varied from 9-16 years. Similarly, the mean age at menarche of sisters and mothers were 12.96 years and 14.30 years respectively. To study the height and weight of the respondents, the mean height and weight were $1.50 \mathrm{~m}$ and $45 \mathrm{~kg}$ respectively. The mean BMI of the respondents was $20.08 \mathrm{~kg} / \mathrm{m}^{2}$ and it varied from 12.92-38.07 (Table 1).

Table 1. Descriptive Statistics of mean age at menarche of the participants, their sisters and mothers and BMI.

\begin{tabular}{|lccccc|}
\hline & N & $\begin{array}{c}\text { Mini- } \\
\text { mum }\end{array}$ & $\begin{array}{c}\text { Maxi- } \\
\text { mum }\end{array}$ & Mean & $\begin{array}{c}\text { Std. } \\
\text { Devia- } \\
\text { tion }\end{array}$ \\
Age (years) & 500 & 9 & 18 & 14.69 & 2.25 \\
Height (m) & 500 & 102.50 & 182.88 & 1.50 & 11.14 \\
Weight (kg) & 500 & 30.00 & 72.00 & 45.14 & 6.75 \\
$\begin{array}{l}\text { Age at Menarche } \\
\text { (years) }\end{array}$ & 438 & 9.00 & 16.00 & 12.56 & 1.12 \\
$\begin{array}{l}\text { Mother age } \\
\text { (years) }\end{array}$ & 500 & 11.00 & 19.00 & 14.30 & 1.58 \\
Sister age (years) & 231 & 10.00 & 17.00 & 12.96 & 1.25 \\
BMI $\left(\mathrm{kg} / \mathrm{m}^{2}\right)$ & 500 & 12.92 & 38.07 & 20.08 & 3.41 \\
\hline
\end{tabular}


The mean age at menarche of vegetarian group was 12.41 years as compared to non-vegetarian was 12.59 years which was statistically insignificant $(\mathrm{p}>0.05)$ (Table 2).

\begin{tabular}{|c|c|c|c|c|c|}
\hline Habit & $\mathbf{N}$ & Mean & $\begin{array}{l}\text { Std. Devia- } \\
\text { tion }\end{array}$ & t- test & $\mathbf{P}$ \\
\hline Veg & 58 & 12.41 & 1.06 & -1.106 & 0.37 \\
\hline Non. Veg & 380 & 12.59 & 1.14 & & \\
\hline
\end{tabular}

The mean age at menarche of group having income below 30 thousand was 12.59 yearsas compared to group having income above 30 thousand was 12.50 years which was statistically insignificant $(\mathrm{p}>0.05)$. In correlation analysis, there was weak correlation $(\mathrm{r}=0.01)$ observed between age at menarche and income (Table 3).

\begin{tabular}{|lrrrrrr|}
\hline $\begin{array}{l}\text { Table 3. Mean age (years) at menarche according to } \\
\text { income. }\end{array}$ & $\mathrm{N}$ & Mean & $\begin{array}{c}\text { Std. De- } \\
\text { viation }\end{array}$ & $\begin{array}{c}\text { Std. Error } \\
\text { Mean }\end{array}$ & $\mathrm{p}$ & t- test \\
\hline Income & 294 & 12.59 & 1.13 & 0.06 & & \\
$\begin{array}{l}\text { Below } 30 \text { thou- } \\
\text { sands } \\
30 \text { thousands } \\
\text { and above }\end{array}$ & 144 & 12.50 & 1.11 & 0.09 & 0.77 & 0.44 \\
\hline
\end{tabular}

According to race, the lowest mean age at menarche was observed in Newars (12.31years) and highest mean age at menarche in Brahmin/ Chhetri (12.67 years), followed by age at menarche in Mongoloids (12.52 years) and others (12.56 years).Therefore, race is not the factor of age at menarche, where $\mathrm{p}=0.28$ and $\mathrm{F}=1.27$ and found statistically insignificant $(p>0.05)$ (Table 4). In addition, correlation analysis revealed very weak correlation between age at menarche with sisters and mother's age.

\begin{tabular}{|lcccl|}
\hline $\begin{array}{l}\text { Table 4. Comparison of age (years) at menarche } \\
\text { with race. }\end{array}$ & Mean & Std. Deviation & F & P \\
\hline Race & 12.67 & 1.16 & 1.27 & 0.285 \\
Brahmin/ Chhetri & 12.31 & 1.47 & & \\
Newar & 12.52 & 1.07 & & \\
Mongoloids & 12.61 & 1.02 & & \\
Others & & & \\
\hline
\end{tabular}

\section{DISCUSSION}

The menstruation is a part of the normal physiological phenomenon occurring at reproductive period in females, variation in menarchial pattern is frequently observed among the adolescents. In the present study, the mean age at menarche of school going girls of Jorpati,
Kathmandu was found to be $12.56 \pm 1.12$ years which is less than the study conducted in Palpa and Rupandehi district which was 14.3 years $(n=239)^{17}$, study carried out by other researchers in Pokhara Valley which was $12.69 \pm 0.95 \quad(n=450)^{2}$ and the study carried out on Yanadiat Andra Pradesh $(n=400)$, themean age at menarche of Yanadi women was at $13.46 \pm 1.09$ years. ${ }^{1}$ The increased urbanization can lead to better socio-economic status and dietary habits which can affect in decreasing age at menarche.However, this result is similar to the study conducted by the scientist, where age at menarche was $12.58 \pm 0.07$ years. ${ }^{3}$ Whereas this age at menarche is higher than the study conducted by others $(12.2 \pm 0.9)$ and $(13.5 \pm 0.84)$. $^{11,18}$

The mean age at menarche of the participants was found to be lesser than that of their elder sisters (12.96 \pm 1.25 years) and which was in turn lesser than that of their mothers $(14.30 \pm 1.58)$ which was again lesser than the study carried out by others (sister- $13.4 \pm 1.7$ years and of mothers $14.8 \pm 1.67$ years). ${ }^{2}$ This shows the descending pattern of age at menarche with successive generation. ${ }^{10}$ Many studies have explained such decrease in age at menarche with successive generation as a result of increase in urbanization, better dwelling and smaller family size as compared to previous generation. ${ }^{13,15}$ However, this result is not similar to the other study where, conclusion had made that the US girls were not gaining reproductive potential earlier than in the past. $^{19}$

In this study, the mean age at menarche is negatively associated with BMI. The hormone, Leptin (secreted by fat cells in adipose tissue) can influence the synthesis and secretion of hypothalamicpeptide, which in turn modulate gonadotrophin-releasing hormone $(\mathrm{GnRH})$ release. Rise in GnRH leads to increased production of Luteinizing hormone (LH) and Follicular Stimulating Hormone (FSH). A higher level of FSH and LH causes resultant increase in estrogen level. The rise in level of Estrogen and pulsatile GnRH secretion leads to initiation of menstruation and eventually create cyclic pattern causing early menstruation. ${ }^{4,15,16}$

Many studies suggested that the age at menarche is influenced by several factors such as biological factors, nutritional factors and geographical factors. ${ }^{11-13}$ In the present study, the mean age at menarche of vegetarian participants was 12.41 \pm 1.06 years and that of non-vegetarian was 12.49 \pm 1.14 . The result is however insignificant because $\mathrm{p}=0.31$. This study is similar to the study conducted 
by others, in which there was delayed onset of menarche of non-vegetarian girls But it is not similar to the study carried out by the other researchers where mean age at menarche of nonvegetarian was $12.68 \pm 0.95$ and of vegetarian was $12.82 \pm 0.81 .^{2}$

Many studies suggested that there is positive association between the socio-economic status of the family and early menarche. ${ }^{2,6}$ In this study there is poor positive association between the income of the family and age at menarche, where the value of correlation and significance were $\mathrm{r}=0.01$ and $\mathrm{p}=0.84$. Likewise in a study conducted in Ghanian school girls, the menarchial age was shown to be affected by social class, ethnic origin of parents, surrounding environment of home. ${ }^{20}$ In this study an Anova test of mean age at menarche of the different races suggested that there was no significant association between them, where $\mathrm{p}=0.28$ and $\mathrm{f}=1.27$ whereas the highest mean age atmenarche was in Brahmin/ Chhetri(12.67 years ) and lowest was in Newar (12.31 years), ${ }^{11}$ followed by age at menarche in Mongoloids (12.52years) and others (12.56years). In Newar the diet pattern is non-vegetarian and they have frequent family gathering/party related to culture. Therefore, they used to take more amount of meat and meat product. These days, the growth hormone is injected to the boiler chicken for business purpose, which may be the cause of early menarche in them. ${ }^{21,22}$ In Brahmin/ Chhetri, the cause of late menarche may be due to genetic influence. ${ }^{11}$
As this study was conducted in Jorpati, Kathmandu, the results wouldnot represent the girls of whole Nepal. If such study can be conducted including the girls of different district of Nepal, it will be more representative to the population of Nepal.

The setting up of a counseling service particularly for adolescent girl would be very beneficial where conceptual idea and preparatory classes on menstrual hygiene, method to cope with minor physical discomfort and further better psychological preparedness would be appreciable. ${ }^{5}$ Therefore we can suggest that, the age at menarche is decreasing in secular trend, the girls will be benefitted and will be psychologically prepared, if it is incorporated in school curriculum when they are at the age of eight years.

\section{CONCLUSIONS}

The present study was conducted to explore the mean age at menarche and associating factors among the Nepali school girls of Jorpati. There was decrease in age at menarche with successive generation as a result of increase in urbanization, better dwelling and smaller family size as compared to previous generation.

\section{ACKNOWLEDGEMENTS}

I would like to thank all the participants who allow me to carry out this study. In addition, I would like to thank Dr. Rajib Chaulagain for critically reading and providing valuable suggestions.

\section{REFERENCES}

1. Tirupati C, TirupatiA. Menarche and Menopause among the Yanadi Tribal Women. IOSR Journal Of Humanities And Social Science. 2014;19(9):3.[Google]

2. Sunuwar L, Saha C, Anupa K, UpadhyayDhungel K. Age at menarche of subpopulation of Nepalese girls. Nepal Med Coll J. 2010;12(3):183-186.[PMID]

3. Dacou-Voutetakis C, Klontza D, Lagos P, et al. Age of pubertal stages including menarche in Greek girls. Annals of human biology. 1983;10 (6):557-563.[DOI][PMID]

4. Guyton A, Hall J. Textbook of Medical Physiology. 12 ed: Saunders; 2006.

5. Wu X, Cai H, Kallianpur A, et al. Age at menarche and natural menopause and number of reproductive years in association with mortality: results from a median follow-up of 11.2 years among 31,955 naturally menopausal Chinese women. PLoS One. 2014;9

\section{(8):e103673.[DOI][PMID]}

6. Aryeetey R, Ashinyo A, Adjuik M. Age of Menarche among basic level school girls in Madina, Accra. African journal of reproductive health. 2011;15(3):113-121.[PMID]

7. Chhaupadi.[Internet]Wikipedia, The Free Encyclopedia. April 5, 2018; https:// en.wikipedia.org/w / in d ex . p h p ? title $=$ Chhaupadi\&oldid $=834422877$. Accessed Nov 4, 2017.

8. Danielle P. 15-Year-Old Girl Found Dead In A Menstrual Hut In Nepal. National Public Radio Dec. 20, 2016; https://www.npr.org/sections/ goatsandsoda/2016/12/20/506306964/15-yearold-girl-found-dead-in-a-menstrual-hut-in-nepal. Accessed 1 April, 2018.

9. Ghimire LV. Unclean \& unseen. Student BMJ. 2005;13.[Google]

10. Pathak PK, Tripathi N, Subramanian S. Secular trends in menarcheal age in India-evidence from the Indian human development survey. PLoS 
Chalise et al. Age at Menarche among the School Going Children of Jorpati, Kathmandu.

One. 2014;9(11):e111027.[DOI][PMID]

11. Sharma S, Deuja S, Saha C. Menstrual pattern among adolescent girls of Pokhara Valley: a cross sectional study. BMC women's health. 2016;16(1):74.[DOI][PMID]

12. Bahrami N, Soleimani MA, Chan YH, Ghojazadeh M, Mirmiran P. Menarche age in Iran: A meta-analysis. Iranian journal of nursing and midwifery research. 2014;19(5):444.[PMID]

13. Dars S, Sayed K, Yousufzai Z. Relationship of menstrual irregularities to BMI and nutritional status in adolescent girls. Pakistan journal of medical sciences. 2014;30(1):141.[DOI][PMID]

14. Jeffcoate N, Tindall VR. Principles of Gynaecology. 5 ed: Butterworths; 1987.

15. Mohsenzadeh-ledari F, Keramat A, Khosravi A. Systematic review and meta-analysis of mean age at menarche in Iranian girls. Caspian Journal of Reproductive Medicine. 2015;1(2):28-34. [Google Scholar]

16. Aryal TR. Age at menarche: differentials and determinants. Journal of Nepal Medical Association. 2004;43(152):71-75.[DOI][PMID]

17. Bhattacharya S. Experiences of girls about their menarche. Journal of Institute of Medicine. 1999;21(1\&2):4.[Google Scholar]

18. Biswas RK, Kapoor A. Age at menarche and menopause among Saharia women-A primitive tribe of Madhya Pradesh. The Anthropologist. 2005;7(2):1-5.[Google Scholar][DOI]

19. Chumlea WC, Schubert CM, Roche AF, et al. Age at menarche and racial comparisons in US girls. Pediatrics. 2003;111(1):110-113.[PMID]

20. Adadevoh S, Agble T, Hobbs C, Elkins TE. Menarcheal age in Ghanaian school girls. International Journal of Gynecology \& Obstetrics. 1989;30(1):63-68.[DOI][PMID]

21. Cogburn LA, Liou SS, Rand AL, McMurtry JP. Growth, metabolic and endocrine responses of broiler cockerels given a daily subcutaneous injection of natural or biosynthetic chicken growth hormone. The Journal of nutrition. 1989;119(8):1213-1222.[DOI][PMID]

22. Yermachenko A, Dvornyk V. Nongenetic determinants of age at menarche: a systematic review. BioMed research international. 2014;2014.[PMID][DOI]

Citation: Chalise U, Pradhan A, Lama CP, Pant PP, Dhungel S. Age at Menarche among the School Going Children of Jorpati, Kathmandu. JCMS Nepal. 2018;14(3):142-6 